\title{
Why Free Relatives Sometimes Behave as Indefinites
}

\author{
Stefan Hinterwimmer \\ Humboldt-Universität zu Berlin
}

\section{Introduction: The Puzzle}

According to the (by now) standard view, (realis) Free Relatives (FRs) have the semantics of (singular or plural) definite descriptions (Jacobson 1995 a. o.): they either denote the unique atomic individual or the maximal sum individual contained in the set denoted by the respective $\mathrm{CP}$, depending on whether there is only one or a plurality of individuals that satisfy the respective predicate. The example in (1a) can accordingly be paraphrased as in (1b).

(1) a. John ate what was on his plate.

b. John ate the thing(s) that was/were on his plate.

There are, however, cases like (2a), (3a) and (4a), where this correspondence between FRs and singular/plural definites breaks down, and where the FRs rather seem to behave as indefinites, as becomes evident by the paraphrases in (2b), (3b) and (4b).

(2) a. What John reads is always/usually/often tasteful.

b. All/most/many things that John reads are tasteful.

(cf. Berman 1991 and Wiltschko 1999)

(3) a. John wants to write what sells well.

b. John wants to write a book that sells well.

(Wiltschko 1999: 705)

a. Wer nimmt, was ihm nicht gehört,

Who takes what to-him not belongs

ist ein Dieb.

is a thief

'Who(ever) takes what does not belong to him is a thief.'

b. Everybody who takes something that does not belong to him is a thief. (Sternefeld 2005: 1)

I would like to thank Cornelia Endriss, Andreas Haida, Manfred Krifka as well as the audiences at SALT XVIII and at the University of Tübingen for helpful discussion and comments. 
In the case of (2a), the quantificational force of the FR seems to vary with the quantificational force of the respective Q-adverb, as shown by the paraphrase in (2b). Quantificational Variability Effects (QVEs) are usually associated with singular indefinites and bare plurals, however, not with singular or plural definites. The pattern in $(2 a)$ is therefore surprising for an account which treats FRs as essentially equivalent to definite descriptions (apart from the fact that they are not marked for a singular/plural contrast).

Note, however, that it is not always impossible for sentences with definite descriptions to get QV-readings (I will come back to this point at the end of section 4). Under certain conditions, which are discussed in detail in Hinterwimmer 2008, such readings are possible. These conditions are not fulfilled in the case of (2a), however, as is evidenced by the fact that the examples in (5) below, where the FR has been replaced by a definite description, do not get QV-reading and are accordingly very odd - unless the individual level predicate be tasteful is re-interpreted as a stage level predicate. The puzzle therefore remains.

a. ${ }^{? ?}$ The book that John reads is usually tasteful.

b. "? The books that John reads are usually tasteful.

Concerning the example in (3a), its meaning can be paraphrased adequately by the sentence in (3b), where the FR has been replaced by an indefinite. In this case, too, replacing the FR by a definite description leads to unacceptability, as evidenced by the examples in (6):

(6) a. ??John wants to write the book that sells well. (Wiltschko 1999: 705)

b. ??John wants to write the books that sell well.

Note, however, that the examples in (6) do not show that definite descriptions are in general incompatible with verbs of creation like write, as Wiltschko (1999) claims. It is just extremely implausible to ascribe to somebody the belief that in all of his belief-worlds (see section 3.1 for an analysis of sentences with want in terms of quantification over possible worlds) there is a unique book that sells well, or the wish to write all books that sell well himself. If we replace the definite description in (6a) by one that makes more sense in this context, however, the sentence becomes perfectly acceptable, as is evidenced by the example in (7):

(7) John wants to write the book that solves all syntactic problems.

This is simply due to the fact that it is much more reasonable for someone to have a unique book that solves all syntactic problems in his belief worlds than a unique 
book that sells well.

Finally, in the case of (4a), the two FRs are interpreted differently: the one in subject position receives a definite or universal-like interpretation, while the one in embedded object position is interpreted existentially. While the interpretation of the subject FR is of course unproblematic for standard accounts of FRs, the interpretation of the embedded object FR is entirely unexpected.

In this paper I argue that the peculiar behavior of FRs exemplified by the examples in (1)-(4) is best solved by assuming that FRs are ambiguous between an interpretation as ordinary extensional maximal sum individuals and an interpretation as kinds (see Carlson 1977), i.e. as functions from worlds/situations into the maximal sum individuals that satisfy the respective predicate with respect to the world/situation considered. Since an entity of type $<s, e>$-cannot function as an argument of an object-level predicate, existential quantification over instances of the respective kind is triggered whenever a kind-denoting FR needs to be combined with an object-level predicate. Indefinite-like readings of FRs like the ones above are thus a consequence of FRs sometimes being interpreted as kinds instead of ordinary extensional sum individuals. But before I turn to the details of this proposal and its consequences, we will first have a brief look at two previous attempts to solve the puzzle posed by the examples in (1) vs. the ones in (2)-(4).

\section{Previous Proposals}

\subsection{Wiltschko (1999)}

Wiltscko (1999), who concentrates on examples like the ones in (2)-(4), analyses FRs along the following lines: the clause-initial wh-term is not part of the $\mathrm{CP}$, but is the external head of the clause, while the CP modifying the head contains an empty operator in its specifier. Since the $w h$-terms are treated analogously to the indefinite wh-pronouns wer (who), was (what) etc. in German, FRs are interpreted accordingly.

While this gives us the right results for cases like (2a) and (3a), it does not work for episodic sentences like the examples in (1), and for the subject-FR in (4a). Concerning examples like (1a, b), Wiltschko (1999) proposes that in such cases the FR is interpreted as a specific indefinite (while the FRs in examples like (2a) and (3a) are interpreted as unspecific indefinites). This, however, is problematic for the following reasons: first, wh-pronouns like wer and was can only be interpreted non-specifically. Second, and more importantly, Wiltschko (1999) predicts that the FR in an episodic sentence like (8a) below should be interpreted identically to the specific indefinite in (8b). This, however, is not the case: the FR only gets an exhaustive interpretation, i.e. in a situation where John recommended five papers to Mary, (8a) is false if Mary read only three of them. 
(8b), in contrast, is true in this situation.

a. Mary read what John recommended to her last Friday.

b. Mary read certain/some books that John recommended to her last Friday.

Note that Wiltschko (1999) in addition to examples like the ones in (2)-(4) also cites some episodic sentences as evidence for her claim that FRs are interpreted as indefinites. Her arguments do not go through, however, as shown in Hinterwimmer (2008). While space prevents me from a more detailed discussion of her examples in this paper, I would like to mention the following case as an illustration:
a. * Mary repeatedly killed the ant.
b. Mary repeatedly killed an ant.
c. Mary repeatedly killed what(ever) was in her way.
(Wiltschko 1999: 704)

According to Wiltschko (1999), the examples above show that FRs even in episodic sentences pattern with indefinites, not with definites, which she assumes to be incompatible with once only predicates (de Swart 1993) like kill that are modified by adverbs of frequency like repeatedly. Note, however, that (9a) improves dramatically if the definite DP is modified by a relative clause like the one in (10) below, which is similar to the FR in (9c):

Mary repeatedly killed the ant that got in her way.

I take this as evidence that the contrast between (9a) and (9c) does not have anything to do with (in)definiteness, but rather derives from the following fact: in the case of (9c) (as well as in 10) a relative clause CP is present that introduces a situation variable which can be bound by the adverb repeatedly. In the case of (9a), in contrast, there is no such variable. In Hinterwimmer (2008) I show that the presence of situation variables can lead to a relativization of the uniqueness condition associated with the definite determiner in singular definites, and such a relativization is exactly what is required in the examples under discussion: it is of course impossible that there are repeated events of killing one and the same person. It is possible, however, that there are repeated killing events such that for each of those events there is a different unique individual satisfying the respective predicate.

\subsection{Sternefeld (2005)}

Sternefeld (2005), which is just a squib, notes the existence of examples like (4a), 
which are problematic for all existing accounts of FRs, because here two FRs receive different interpretations although they are contained in the same sentence. He does not make a real proposal as to how to solve the problem, but rather suggests that FRs might be ambiguous between an existential and a universal interpretation, and that it would be a topic for future research to determine the exact pragmatic conditions under which one of the two readings is available.

\section{My Proposal}

\subsection{The Basic Idea}

I propose to assume that FRs are ambiguous in the following sense: there always is an empty determiner present which takes the overt $\mathrm{CP}$ (whose specifier contains the $w h$-term) as its complement (cf. Caponigro 2002, 2004). Crucially, this determiner comes in two closely related variants, $D_{1}$ and $D_{2}$. The first one has the denotation of the definite determiner, i.e. it denotes the sigma-operator (Link 1983). Accordingly, it returns an object of type $e$, namely the maximal (sum) individual that satisfies the predicate denoted by the respective $\mathrm{CP}$ with respect to either a contextually given situation or the world of evaluation (by default). Its denotation is given formally in (11a) below. The second one denotes a kind-forming operator that returns an object of type $\langle s, e\rangle$, i.e. a function that for each possible world or situation returns the maximal (sum) individual satisfying the respective predicate in that world (cf. Chierchia 1998 and Dayal 2004). Its denotation is given formally in (11b).

a. $\llbracket \mathrm{D}_{1} \rrbracket=\lambda \mathrm{P}_{<\mathrm{e},<\mathrm{s}, \mathrm{\downarrow}>} . \sigma\left\{\mathrm{x}: \mathrm{P}(\mathrm{x})\left(\mathrm{s}_{1}\right)\right\}$,

where $s_{1}$ is a free variable that may either be resolved to a contextually salient situation or to the world of evaluation by default.

b. $\llbracket\left[\mathrm{D}_{2} \rrbracket=\lambda \mathrm{P}_{<\mathrm{e},<\mathrm{s}, \mathrm{t}>} . \lambda \mathrm{s} . \sigma\{\mathrm{x}: \mathrm{P}(\mathrm{x})(\mathrm{s})\}\right.$

Note that (11b) corresponds to the empty $\mathrm{D}^{0}$ Chierchia (1998) assumes to be present in bare plurals in languages like English. Accordingly, I assume that FRs employing $D_{2}$ have in principle the same interpretative options as bare plurals in English (but see section 4.1 for a qualification of this statement). Consequently, if they become the argument of an object-level predicate like read, write or take, existential quantification over instances of the respective kind is triggered. Furthermore, it is well known that in German kinds may either be realized by bare plurals or by plural definites (Krifka et al. 1995), while in Italian only plural definites are acceptable as kind-denoting terms in most syntactic environments (see Chierchia 1998 and Longobardi 2001 for discussion). Since in these languages, too, plural definites can also be interpreted as ordinary extensional maximal sum individuals, we find the same ambiguity in the definite determiner 
that I assume to be present in the empty determiner coming with FRs. I will come back to this point in section 4.1 .

My account now makes the following prediction: existential readings of FRs are only possible if the predicate denoted by the respective $\mathrm{CP}$ is general enough for kind formation (more on this in section 4.1). Otherwise, it can only be shifted via $D_{l}$. This prediction is borne out: in an example like (3a), the existential reading disappears if the temporally unspecific $\mathrm{CP}$-predicate is replaced by a temporally specific predicate, as shown in (12a).

(12) a. John wants to write what Mary suggested to him last Friday

b. John wants to write the book(s) that Mary suggested to him last Friday.

c. John wants to write a book/some books that Mary suggested to him last Friday.

In the case of (12a), the FR can only be interpreted as denoting the maximal (sum) individual satisfying the CP-predicate. Accordingly, the paraphrase in (12b) is adequate, not the one in (12c): in a situation where Mary suggested to John that he should write a book about kangaroos, a book about Q-adverbs and a book about Elvis, (12a) is only true if John wants to write all of this books, while in a situation where Mary only suggested to John that he should write a book about kangaroos, it is sufficient that he wants to write that book.

Before we turn to some obvious questions raised by this account, let us have a closer look at how the readings that were problematic for the standard account are generated in detail.

\subsection{The Problematic Readings in Detail}

Consider (2a) first, repeated below as (13a), where the FR gets shifted via $D_{2}$. Let us first turn to the interpretation of the overt $\mathrm{CP}$, which I assume to be a function from individuals into a function from situations/possible worlds into truth values. Concerning the wh-pronoun what, I follow Caponigro $(2002,2004)$ in assuming that it denotes the object given in (13b).

(13) a. What John reads is always/usually/often tasteful.

b. [I what $\rrbracket=\lambda \mathrm{P}_{<\mathrm{e},<\mathrm{s}, \mathrm{t}>>} \cdot \lambda \mathrm{x}$. $\lambda \mathrm{s}$. thing ${ }^{\prime}(\mathrm{x})(\mathrm{s}) \wedge \mathrm{P}(\mathrm{x})(\mathrm{s})$

c. $\left[\left[\mathrm{c}^{\prime} \lambda 1\right.\right.$ John reads 1$] \rrbracket=\lambda \mathrm{y} \cdot \lambda \mathrm{s} . \exists \mathrm{s}^{\prime} \leq \mathrm{s}\left[\operatorname{read}^{\prime}(\mathrm{y})(\mathrm{j})\left(\mathrm{s}^{\prime}\right)\right]=$

d. $\left[\right.$ [ $\left[\mathrm{CP}\right.$ what $\left[\mathrm{C}^{\prime} \lambda 1\right.$ John reads 1$\left.]\right]=$ $=\lambda \mathrm{x} . \lambda \mathrm{s}$. thing ${ }^{\prime}(\mathrm{x})(\mathrm{s}) \wedge \exists \mathrm{s}^{\prime} \leq \mathrm{s}\left[\operatorname{read}^{\prime}(\mathrm{x})(\mathrm{j})\left(\mathrm{s}^{\prime}\right)\right]$

The trace it leaves behind in its base position is interpreted as a variable of type $e$ which gets bound by a lambda-operator inserted directly beneath the landing position of the wh-pronoun in Spec, CP. Note that I assume the world/situation 
argument of the relative clause verb to be bound by a covert existential quantifier that is inserted at the TP-level by default, i.e. in the absence of an overt Q-adverb. Consequently, the sister of the wh-pronoun is interpreted as shown in (13c), and the entire overt $\mathrm{CP}$ as shown in (13d).

The next step now consists in applying the denotation of $D_{2}$ to the object given in (13d), as shown in (14a). The kind thus created has to be shifted to an existential quantifier over its realizations, as shown in (14b), because it becomes the argument of the object-level predicate is tasteful:

a. $\left[\left[\mathrm{DP}_{2} \mathrm{D}_{2}\left[\mathrm{CP}\right.\right.\right.$ what $\left[\mathrm{C}^{\prime} \lambda 1\right.$ John reads 1$\left.\left.]\right]\right] \rrbracket=$

$\lambda \mathrm{P}_{<\mathrm{e},<\mathrm{s}, \mathrm{t}>>} . \lambda \mathrm{s} . \sigma\{\mathrm{x}: \mathrm{P}(\mathrm{x})(\mathrm{s})\}$

$\left(\lambda x \lambda\right.$ s. thing $\left.{ }^{\prime}(x)(s) \wedge \exists s^{\prime} \leq s\left[\operatorname{read}^{\prime}(x)(j)\left(s^{\prime}\right)\right]\right)=$ $\lambda \mathrm{s} . \sigma\left\{\mathrm{x}\right.$ : thing $\left.\mathrm{g}^{\prime}(\mathrm{x})(\mathrm{s}) \wedge \exists \mathrm{s}^{\prime} \leq \mathrm{s}\left[\operatorname{read}^{\prime}(\mathrm{x})(\mathrm{j})\left(\mathrm{s}^{\prime}\right)\right]\right\}$

b. $\lambda \mathrm{s} . \sigma\left\{\mathrm{x}\right.$ : thing $\left.(\mathrm{x})(\mathrm{s}) \wedge \exists \mathrm{s}^{\prime} \leq \mathrm{s}\left[\operatorname{read}^{\prime}(\mathrm{x})(\mathrm{j})\left(\mathrm{s}^{\prime}\right)\right]\right\} \Rightarrow$

$\lambda \mathrm{k}_{<\mathrm{s}, \mathrm{e}>} . \lambda \mathrm{P}_{<\mathrm{e},<\mathrm{s}, \mathrm{t}>>} \cdot \lambda \mathrm{s}_{2} . \exists \mathrm{y}\left[\operatorname{Real}(\mathrm{k})(\mathrm{y})\left(\mathrm{s}_{2}\right) \wedge \mathrm{P}(\mathrm{y})\left(\mathrm{s}_{2}\right)\right]$

$\left(\lambda \mathrm{s} . \sigma\left\{\mathrm{x}\right.\right.$ : thing $\left.\left.{ }^{\prime}(\mathrm{x})(\mathrm{s}) \wedge \exists \mathrm{s}^{\prime} \leq \mathrm{s}\left[\operatorname{read}^{\prime}(\mathrm{x})(\mathrm{j})\left(\mathrm{s}^{\prime}\right)\right]\right\}\right)=$

$\lambda \mathrm{P}_{<\mathrm{e},<\mathrm{s}, \mathrm{t}>>} \cdot \lambda \mathrm{s}_{2} . \exists \mathrm{y}\left[\operatorname{Real}\left(\lambda \mathrm{s} . \sigma\left\{\mathrm{x}: \operatorname{thing}^{\prime}(\mathrm{x})(\mathrm{s}) \wedge\right.\right.\right.$

$\left.\left.\left.\wedge \exists \mathrm{s}^{\prime} \leq \mathrm{s}\left[\operatorname{read}^{\prime}(\mathrm{x})(\mathrm{j})\left(\mathrm{s}^{\prime}\right)\right]\right\}\right)(\mathrm{y})\left(\mathrm{s}_{2}\right) \wedge \mathrm{P}(\mathrm{y})\left(\mathrm{s}_{2}\right)\right]$,

where 'Real $(\mathrm{k})(\mathrm{y})\left(\mathrm{s}_{2}\right)$ ' means for ' $\mathrm{y}$ realizes $\mathrm{k}$ at $\mathrm{s}_{2}$ '.

The QV-readings of (2a)/(13a) now come about in the following way: the existential quantifier in (14b) is interpreted in the restrictor as well as in the nuclear scope of the respective Q-adverb, which I assume to be a selective quantifier over minimal situations (cf. von Fintel 1994 a. o.), as shown in (15).

[[ what John reads is always tasteful 》 =

$\lambda \mathrm{s} \forall \mathrm{s}^{\prime} \leq \mathrm{s}$. [min $\left(\mathrm{s}^{\prime}, \lambda \mathrm{s}_{2} . \exists \mathrm{y}\left[\operatorname{Real}(\mathrm{THINGS}\right.\right.$ THAT JOHN READS $\left.\left.)(\mathrm{y})\left(\mathrm{s}_{2}\right)\right]\right) \rightarrow$

$\rightarrow \exists \mathrm{s}_{3}\left[\mathrm{~s}^{\prime} \leq \mathrm{s}_{3} \wedge \min \left(\mathrm{s}_{3}, \lambda \mathrm{s}_{4} . \exists \mathrm{y}\left[\operatorname{Real}(\mathrm{THINGS}\right.\right.\right.$ THAT JOHN READS $)(\mathrm{y})\left(\mathrm{s}_{4}\right) \wedge$ $\left.\left.\left.\left.\wedge \operatorname{tasteful}(\mathrm{y})\left(\mathrm{s}_{4}\right)\right]\right)\right]\right]$

'All minimal situations containing a realization of the kind THINGS THAT JOHN READS can be extended to a minimal situation where a realization of that kind is tasteful'.

Note that I assume the quantifier in (14b) to become an object of the right type to be interpreted in the restrictor of the Q-adverb (namely one of type $<s, t>$ ) in the following way: it is applied to the dummy predicate $\lambda x \lambda s$. $\operatorname{in}(x)(s)$ (see Hinterwimmer 2008 for details). This step is omitted here because the result it gives us is equivalent to the one shown in (15).

Concerning (3a), which is repeated here as (16a), the first two steps are parallel to the case of $(2 a) /(13 a)$. Following Heim's (1992) analysis of want in 
terms of quantification over belief worlds, we thus get a reading for the sentence that can be paraphrased as given in (16b).

(16) a. John wants to write what sells well.

b. For every world $w$ in the set of John's epistemic alternatives to $w_{0}$ it is the case that any world $\mathrm{w}^{\prime}$ that is maximally similar to $w$ in which there is a realization $y$ of the kind THINGS THAT SELL WELL such that John writes $y$ in $w^{\prime}$ is more desirable to John than any world $w^{\prime \prime}$ maximally similar to $w$ such there is no realization $y$ of that kind such that John writes $y$ in $w^{\prime \prime}$.

Let us finally turn to (4a), repeated here as (17a), whose most salient reading is paraphrased in (17b) again:

a. Wer nimmt, was ihm nicht gehört,

Who takes what to-him not belongs

ist ein Dieb.

is a thief

'Who(ever) takes what does not belong to him is a thief.'

b. Everybody who takes something that does not belong to him is a thief'.

Note that in this case the embedded object-FR, whose denotation is given in (18a), has to be shifted to an existential quantifier, as shown in (18b), before the denotation of the subject FR can be computed, i.e. before $D_{2}$ can be applied to the denotation of the $\mathrm{CP}$ in subject position. This gives us (18c): the partial function from worlds/situations $s$ into the maximal sum individuals $x$ that are human in $s$ such that there is a situation $s_{4}$ that is a part of $s$ such that $s_{4}$ contains a realization $u$ of the kind things that do not belong to $x$ such that $x$ takes $u$ in $s_{4}$. Shifting this object to an existential quantifier then gives us the object in (18d) as the final denotation of the subject-FR.

a. 【[ was ihm nicht gehört $\rrbracket=$ $\lambda \mathrm{s}_{2} . \sigma\left\{\mathrm{u}\right.$ : thing $(\mathrm{u})\left(\mathrm{s}_{2}\right) \wedge \neg \exists \mathrm{s}_{3} \leq \mathrm{s}_{2}$ [belong_to $\left.\left.{ }^{\prime}(\mathrm{u})(\mathrm{x})\left(\mathrm{s}_{3}\right)\right]\right\}$

b. $\lambda \mathrm{s} . \exists \mathrm{s}_{4} \leq \mathrm{s}\left[\exists \mathrm{z}\left[\operatorname{Real}\left(\lambda \mathrm{s}_{2} . \sigma\left\{\mathrm{u}: \operatorname{thing}(\mathrm{u})\left(\mathrm{s}_{2}\right) \wedge\right.\right.\right.\right.$

$$
\begin{array}{r}
\left.\left.\wedge \neg \exists \mathrm{s}_{3} \leq \mathrm{s}_{2}\left[\text { belong_to }^{\prime}(\mathrm{u})(\mathrm{x})\left(\mathrm{s}_{3}\right)\right]\right\}\right)(\mathrm{z})\left(\mathrm{s}_{4}\right) \wedge \\
\left.\left.\left.\wedge \operatorname{take}(\mathrm{z})(\mathrm{x})\left(\mathrm{s}_{4}\right)\right]\right]\right\}
\end{array}
$$

c. 【[ wer nimmt was ihm nicht gehört $\rrbracket=$ $\lambda \mathrm{s} . \sigma\left\{\mathrm{x}: \operatorname{human}(\mathrm{x})(\mathrm{s}) \wedge \exists \mathrm{s}_{4} \leq \mathrm{s}\left[\exists \mathrm{z}\left[\operatorname{Real}\left(\lambda \mathrm{s}_{2} . \sigma\left\{\mathrm{u}: \operatorname{thing}(\mathrm{u})\left(\mathrm{s}_{2}\right) \wedge\right.\right.\right.\right.\right.$

$$
\left.\left.\wedge \neg \exists \mathrm{s}_{3} \leq \mathrm{s}_{2}\left[\text { belong_to }^{\prime}(\mathrm{u})(\mathrm{x})\left(\mathrm{s}_{3}\right)\right]\right\}\right)(\mathrm{z})\left(\mathrm{s}_{4}\right) \wedge
$$




$$
\left.\left.\left.\wedge \operatorname{take}(\mathrm{z})(\mathrm{x})\left(\mathrm{s}_{4}\right)\right]\right]\right\}
$$

d. $\lambda \mathrm{P}_{<\mathrm{e},<s, \downarrow>>} \lambda \mathrm{s}^{\prime} . \exists \mathrm{y}[\operatorname{Real}(\lambda \mathrm{s} . \sigma\{\mathrm{x}: \operatorname{human}(\mathrm{x})(\mathrm{s}) \wedge$

$$
\begin{array}{r}
\exists \mathrm{s}_{4} \leq \mathrm{s}\left[\exists \mathrm { z } \left[\operatorname { R e a l } \left(\lambda \mathrm{s}_{2} . \sigma\left\{\mathrm{u}: \operatorname{thing}(\mathrm{u})\left(\mathrm{s}_{2}\right) \wedge\right.\right.\right.\right. \\
\left.\left.\wedge \neg \exists \mathrm{s}_{3} \leq \mathrm{s}_{2}\left[\text { belong_to }(\mathrm{u})(\mathrm{x})\left(\mathrm{s}_{3}\right)\right]\right\}\right)(\mathrm{z})\left(\mathrm{s}_{4}\right) \wedge \\
\left.\left.\left.\left.\wedge \operatorname{take}(\mathrm{z})(\mathrm{x})\left(\mathrm{s}_{4}\right)\right]\right]\right\}\right)(\mathrm{y})\left(\mathrm{s}^{\prime}\right) \wedge \\
\left.\wedge \mathrm{P}(\mathrm{y})\left(\mathrm{s}^{\prime}\right)\right]
\end{array}
$$

Let us now assume that (4a)/(17a) contains a covert generic operator with quasiuniversal force (see Krifka et al. a.o.), and that the object in (18d) is interpreted in the restrictor as well as in the nuclear scope of this operator, analogous to the cases with overt Q-adverbs discussed above. This gives us the reading paraphrased in (19) as the final denotation of (17a):

(19) In general, minimal situations $s$ that contain a realization of the kind PERSONS $X$ SUCH THAT THERE IS A SITUATION $S^{\prime}$ SUCH THAT THERE IS A REALIZATION $U$ OF THE KIND 'THINGS THAT DO NOT BELONG TO $X$ IN $S$ ' can be extended to a minimal situation $s^{\prime \prime}$ such that a realization of the kind PERSONS $X$ SUCH THAT $\ldots$ in $s^{\prime \prime}$ is a thief in $s^{\prime \prime}$.

Crucially, the minimal situations that the generic operator quantifies over contain a realization of the kind (that can be informally characterized as) persons that at least once took something that didn't belong to them, not the kind persons that take everything that doesn't belong to them. Consequently, the casual thieves are (indirectly) counted as well as the professional ones, and we can account for Sternefeld's (2005) observation that the subject-FR has quasi-universal force, while the embedded object-FR has existential force.

This is due to the fact already mentioned above that because of being embedded inside the subject-FR the kind denoted by the object-FR has to be shifted to an existential quantifier before $D_{2}$ applies to the FR-CP in subject position. Consequently, it is only the existential quantifier corresponding to the subject-FR which is indirectly quantified over by the generic operator, not the one corresponding to the object-FR, which is simply too deeply embedded inside the subject-FR.

We thus have a solution to the puzzle posed by Sternefeld's (2005) example that two FRs contained within the same sentence have (seemingly) different quantificational forces. Note, however, that in my account both FRs are treated uniformly insofar as they are both interpreted as kinds first, and are then shifted to existential quantifiers over realizations of the respective kind. The fact that the subject-FR has quasi-universal force is simply due to its being interpreted in the restrictor of the covert generic operator. In other words, (4a)/(17a) does not exemplify the ambiguity between an interpretation as extensional maximal sum individuals and an interpretation as kinds that I assume to be present in FRs. I thus disagree with Sternefeld (2005), who assumes the quasi-universal 
interpretation of the subject-FR to be equivalent to the interpretation as maximal sum individuals that FRs receive in episodic sentences.

Having presented the basics of my account as well as the technical details of how it generates the right readings of the problematic examples introduced in section 1 , I will now turn to a discussion of some questions it raises.

\section{Further Issues}

\subsection{Questions Raised by My Account}

My account raises (at least) the following questions:

(A) Why are bare plurals in English not ambiguous in the same way as FRs, i.e. why can they only be combined with $D_{2}$, not with $D_{1}$ ?

(B) Why is temporal (non-)specificity the decisive criterion with respect to the availability of a kind(-like) interpretation for FRs, which then leads to an existential interpretation in the presence of object-level predicates?

(C) Why do temporally non-specific FRs not get existential interpretations in episodic sentences such as (20)?

(20) Yesterday, John took what does not belong to him.

The FR in (20) can only be interpreted as referring to some contextually salient thing that does not belong to John. The sentence accordingly does not receive the interpretation paraphrased in (21a), but only the one paraphrased in (21b).

(21) a. Yesterday, John took something that does not belong to him.

b. Yesterday, John took the unique (contextually salient) thing that does not belong to him.

Let us turn to the question in (A) first. Note that determiners in English - with the exception of those, which is demonstrative, however - can never be combined with a CP directly, but always need at least a dummy NP like ones as their complement, as shown by the contrast between (22a) and (22b):

(22) a. *The, who came to John's party yesterday had a really good time.

b. The ones who came to John's party yesterday had a really good time. 
Therefore, choosing the definite determiner instead of $D_{1}$ is not an option in the case of FRs, which by definition do not contain an external NP. In the case of bare plurals, in contrast, ambiguity can be avoided by choosing the overt definite determiner. In the case of bare plurals, the absence of a definite determiner is therefore automatically interpreted as an indication that $D_{2}$ has been chosen.

Concerning (B), note that the choice between pare plurals and plural definites also largely depends on the temporal (un)specificity of the respective predicates, not on criteria like "forming a natural class", "being well-established" or characterizing a set with large cardinality, as evidenced by the examples in (23) (see Endriss and Hinterwimmer 2006 and Hinterwimmer 2008 for more details):

(23) a. (The) Norwegian students who wear thick green socks are usually happy. (cf. Greenberg 2003)

b. (??The) mosquitoes at the open-air concert yesterday evening were surprisingly large.

In the case of (23a), a bare plural has to be chosen in order to ascribe the property of being happy most of the time to the totality of Norwegian students wearing thick green socks, in spite of the fact that the NP-predicate neither characterizes a natural nor a well-established class. If the plural definite is chosen, the subject DP is automatically understood to refer not to the totality of students wearing thick green socks, but to a plurality of Norwegian students that have been introduced before. In other words, the property can be understood to be relativized with respect to a particular contextually given situation and is thus made temporally specific. In the case of (23b), in contrast, where the temporal adverb yesterday evening makes the NP predicate necessarily temporally specific, the definite article has to be chosen in order for the sentence to be fully acceptable, in spite of the fact that the set characterized by the predicate is presumably extremely large.

On the other hand, neither spatial specificity nor being located within a clearly delimited time interval seems to make the presence of the definite determiner obligatory, as long as the respective time interval is large enough. This is evidenced by the examples in (24) (from Hinterwimmer 2008: 203):

a. People who enter this room always like the paintings on the wall.

b. People who studied linguistics in the eighties usually admire Chomsky.

In light of these facts, I suggest that $D_{l}$ can only be applied to properties if it can be assumed that the resulting function of type $\langle s, e\rangle$ yields a defined result for a large enough number of situations, i.e. if there are enough situations containing individuals which satisfy the respective predicate. Otherwise, either $D_{2}$ (in the 
case of properties denoted by a $\mathrm{CP}$ ) or the overt definite determiner (in the case of properties denoted by an NP) has to be chosen.

Before I try to answer the question in (C), I would like to draw the reader's attention to the following fact, which was already mentioned in the introduction: in German, either bare plurals or plural definites can be used to refer to kinds, as evidenced by the examples in (25).
a. (Die) Dinosaurier sind ausgestorben.
(the) dinosaurs are extinct.
'Dinosaurs are extinct'.
b. (Die) Affen sind meistens/manchmal/immer schlau.
(the) apes are usually/sometimes/always smart
'Apes are sometimes/usually/always smart'.

In other words, plural definites seem to be ambiguous in German in exactly the same way as FRs are in general, since they of course can still be used to refer to unique contextually salient maximal sum individuals like the one in (26):

(26) Die Affen, die Peter gestern im $\begin{aligned} & \text { Zoo gesehen hat, } \\ & \text { The apes REL }\end{aligned}$
waren wirklich $\quad$ schlau.
were really smart
'The apes that Peter has seen in the zoo yesterday were really smart'.

Note, however, that as soon as we turn away from sentences with kind-level predicates like (25a), adverbially quantified sentences like (25b) or generic ones, and have a look at episodic sentences, bare plurals can no longer be replaced by plural definites salva veritate, and plural definites cease to be ambiguous:
a. Ich hab gestern im Zoo Affen gesehen. I have yesterday in-the zoo apes seen. 'Yesterday in the zoo, I have seen apes'.
b. Ich hab gestern im Zoo die Affen gesehen. I have yesterday in-the zoo the apes seen. 'Yesterday in the zoo, I have seen the apes'.

While the bare plural in (27a) receives the existential reading we expect in episodic sentences with object-level predicates, the plural definite in (27b) does not get an existential interpretation, but can only be understood to refer to a contextually salient plurality of apes like the apes you told me about etc. Similar effects obtain in Italian, where in most syntactic environments only plural definites, but no bare plurals can be used for kind-reference (see Longobardi 2001 for discussion). Crucially, however, while plural definites behave like bare plurals 
in English and German in sentences with kind-level predicates and in adverbially quantified and generic sentences, as evidenced by the examples in (28a-c) below, this correspondence breaks down in episodic sentences like (28d): there, they can only be interpreted as unique extensional sum individuals, and do not get an existential interpretation (see Dayal 2006 for discussion).

$$
\begin{aligned}
& \text { a. *(I) cani sono diffusi. } \\
& \text { the dogs are widespread }
\end{aligned}
$$

'Dogs are widespread'.

$$
\begin{aligned}
\text { b. } *(\mathrm{I}) & \text { cani abbaiano. } \\
\text { the } & \text { dogs bark }
\end{aligned}
$$

'Dogs bark'.

(Dayal 2006: 18)
c. * (I) cani sono spesso intelligenti. the dogs are often intelligent. 'Dogs are often intelligent'.

d. I cani stanno abbaiano. The dogs are barking 'The dogs are barking'.

(Dayal 2006: 19)

The facts from German and English show that the question asked in (C) is not peculiar to my account of FRs, but rather an incarnation of a puzzle we encounter when we turn to languages like German and Italian, where the ambiguity between an interpretation as a kind and an interpretation as an extensional maximal sum individual that I assume to be present in FRs is found in plural definites as well. From the present perspective, this puzzle can be phrased as follows: why can only unambiguously kind-denoting terms be shifted to an existential interpretation in episodic sentences, while ones that are ambiguous between a kind denotation and an interpretation as extensional sum individuals only get the latter reading in such sentences?

Note that in the case of unambiguously kind-denoting terms, there is no other choice than shifting them to existential quantifiers over realizations of the respective kind if they are to be combined with object-level predicates. In the case of terms that can either denote kinds or extensional sum individuals, in contrast, there is always the option of interpreting them as extensional maximal sum individuals and resolving the free situation variable to some contextually salient situation in such cases. Since this is more economical than interpreting the respective term as a kind first, and shifting it to an existential quantifier in the next step, it is expected to be the preferred option. Seen this way, it is not 
surprising that FRs in general and plural definites in German and English only receive an interpretation as extensional sum individuals in episodic sentences. It is surprising, however, that they ever get indefinite-like interpretations, since in principle there would always be the more economical option of interpreting them as extensional maximal sum individuals.

With this in mind, let us have another look at the examples discussed in this paper where FRs receive an indefinite-like interpretation. First, there are adverbially quantified sentences like (2a), where the quantificational force of the FR varies with the quantificational force of the respective Q-adverb. I argued that this is a consequence of the FRs being shifted to an existential quantifier that is interpreted in the restrictor of the respective Q-adverb. Second, we have mixed cases like (4a), where the matrix subject-FR gets a quasi-universal interpretation, while the embedded object-FR gets an existential interpretation. I argued that in such cases both FRs are shifted to an existential quantifier, and the subject FR is interpreted in the restrictor of the covert generic operator. Consequently, it receives generic force indirectly, while the object FR - because of its being more deeply embedded - retains its existential force. Third, we have the case of (3a), where the FR is shifted to an existential quantifier that is interpreted in the nuclear scope of a modal operator, namely the verb want.

What all these examples have in common is that overt or covert quantification over situations or possible worlds is involved, while no such quantification is involved in the case of episodic sentences, which describe a single situation that is located within the world of evaluation. In light of the fact that kinds are functions from situations/possible worlds into maximal sum individuals, it is not too surprising that there is an affinity between quantification over worlds or situations and a primary interpretation as a kind (that is then shifted to an existential quantifier over realizations of the respective kind): even after existential type-shifting has applied, the resulting proposition does not make a statement about a single individual, since the individuals realizing the respective kind vary with the situations/worlds quantified over - no matter whether the FR is interpreted in the restrictor or the nuclear scope of the respective quantifier.

In episodic sentences, in contrast, shifting a kind to an existential quantifier causes the resulting proposition to not only make a statement about a single situation, but also about a single individual. While this does not seem to be strictly prohibited, as the case of bare plurals occurring in episodic sentences in English and German shows, it makes intuitive sense to see it as an option that is blocked in cases where another option is available - namely the one of interpreting the respective term as an extensional sum individual and thus a particular individual in the first place. The same reasoning applies to the case of plural definites in German and Italian, which also do not get an existential interpretation in episodic sentences, but may receive an indefinite-like interpretation in adverbially quantified an generic sentences (see Dayal 2006 for a related proposal). 
Note that we could even go one step further and claim that existential type-shifting may never apply to kind-denoting terms in episodic sentences, but only in ones involving quantification over situations/possible worlds. We would then have to follow Krifka (2004) in assuming that bare plurals are ambiguous between an existential interpretation and an interpretation as a kind in languages like English and German. Consequently, the existential interpretation of bare plurals in episodic sentences would not result from type-shifting, but from ambiguity resolution, and FRs in general and plural definites in German and Italian would be the only kind-denoting terms to which existential type-shifting may apply - namely in the presence of a quantifier over situations/possible worlds. I will not pursue this line of analysis further, however, since it is not central to my concerns in this paper.

\subsection{Further Evidence for My Account}

As already mentioned in section 1 , not only singular indefinites and bare plurals, but also plural definites receive QV-readings under certain conditions (which are discussed in detail in Hinterwimmer 2008). Endriss and Hinterwimmer (2006) and Hinterwimmer (2008) show that if we compare bare plurals modified by relative clauses with plural definites modified by relative clauses, it becomes evident that the availability of QV-readings is more restricted in the latter than in the former: in the case of plural definites the tense marking of the matrix verb has to agree with the tense marking of the relative clause verb, while in the case of bare plurals this is not required. To see this, consider the examples in (29):

a. Things that were bought in the eighties were/are usually ugly.

b. The things that Mary bought during her holiday were ? $^{\text {? }}$ are usually ugly.

Both variants in (29a) easily get a QV-reading that can be paraphrased as Most things that were bought in the eighties are ugly and Most things that were bought in the eighties were ugly, respectively. In the case of (29b), matters are different: only the variant where both the relative clause verb and the matrix verb are marked for past tense receives a QV-reading, which can be paraphrased as Most things that Mary bought during her holiday were ugly. The variant where the relative clause verb is marked for past tense, while the matrix verb is marked for present tense, does not get a QV-reading, in contrast, and is accordingly odd unless the individual level predicate ugly is re-interpreted as a stage level predicate.

Interestingly, the same contrast that we see between bare plurals and plural definites can be observed between temporally unspecific FRs and temporally specific FRs, as evidenced by the examples in (30): 
a. What was bought in the eighties was/is usually ugly.

b. What Mary bought during her holidays was $/$ ? is usually ugly.

This parallel between bare plurals and temporally unspecific FRs, on the one hand, and plural definites and temporally specific FRs, on the other, in and of itself lends further support to the account argued for in this paper, according to which temporally unspecific FRs are interpreted as kinds, which under certain conditions can be shifted to existential quantifiers over realizations of the respective kind, while temporally specific FRs are interpreted as extensional maximal sum individuals.

Let us now turn to the explanation Endriss and Hinterwimmer (2006) and Hinterwimmer (2008) give for the contrast between bare plurals and plural definites. The basic idea can be summarized as follows: situations quantified over have to be located in a time interval that is determined on the basis of contextually salient information. In cases like (29b), where the plural definite that is interpreted in the restrictor of the Q-adverb is modified by a relative clause, the temporal trace of the situation introduced by the relative clause counts as maximally salient. Therefore, the situations quantified over have to be located within the temporal trace of the relative clause situation.

In the first variant of (29b), this is unproblematic: the situations quantified over are located within the temporal trace of the complex situation that comprises all situations of buying something that took place in the eighties. Consequently, these situations, each of which contains an atomic part of the maximal sum individual denoted by the plural definite (see Hinterwimmer 2008 for a detailed account of how this is ensured), are located within the eighties. For the sentence to be true, it is required that in most of these situations $s$ the thing that was bought in $s$ was ugly in $s$, where the past tense marking of the matrix verb adds the (superfluous) information that the situations of the respective thing being ugly took place before the time of utterance. There is nothing incoherent or contradictory about such a statement, and because of the 1:1 correspondence between the atomic parts of the maximal sum individual that is interpreted in the restrictor of the Q-adverb, and the situations quantified over, we get a $\mathrm{QV}$ reading.

In the case of the second variant in (29b), matters are different: on the one hand, the situations quantified over are again located within the temporal traces of the respective buying situations that took place in the eighties. On the other hand, because of the present tense marking of the matrix verb, it is required that most of these situations are situations of the respective thing being ugly whose temporal traces include the speech time. Since the past tense marking of the relative clause verb furthermore ensures that the eighties are located before the speech time, the sentence is necessarily contradictory on its QV-reading: no situation can at the same time be located in an interval that ends before the time of utterance, and in an interval that includes the time of utterance. 
Let us now turn to bare plurals, which denote kinds, i.e. functions from situations/possible worlds into maximal sum individuals, and accordingly have to be shifted to realizations of the respective kind in the presence of object-level predicates. It is therefore not the semantic object denoted by the bare plural directly that is interpreted in the restrictor of the respective Q-adverb. Consequently, the situations quantified over are not defined on the basis of this semantic object, but rather on the basis of their containing a realization of the kind denoted by the bare plural. Endriss and Hinterwimmer (2006) and Hinterwimmer (2008) now assume that because the relation between the respective DP and the situations quantified over is more indirect in the case of bare plurals than in the case of plural definites, these situations do not necessarily have to be located within the temporal trace of the respective relative clause situation. Consequently, no contradiction arises in the case of non-agreeing tense markings.

If my account is adopted, according to which temporally specific FRs are interpreted in the same way as plural definites, while temporally unspecific FRs are interpreted in the same way as bare plurals, the explanation sketched above carries over straightforwardly to the contrast between temporally specific FRs and temporally unspecific FRs exemplified by the sentences in (30). The facts discussed in this section thus lend further support to my analysis of FRs.

\section{References}

Berman, Stephen: 1991, The Semantics of Open Sentences. Doctoral Dissertation, University of Massachusetts, Amherst.

Caponigro, Ivano: 2002, 'Free Relatives as DPs with a Silent D and a CP Complement', in V. Samiian (ed.) Proceedings of WECOL 2000, California State University, Fresno, CA.

Caponigro, Ivano: 2004, 'The Semantic Contribution of WH-Words and Type Shifts: Evidence from Free Relatives Crosslinguistically', in R. B. Young (ed.), Proceedings of SALT XIV. CLC Publications, Cornell University, Ithaca.

Carlson, Gregory: 1977, Reference to Kinds in English. Doctoral Dissertation, University of Massachusetts, Amherst.

Chierchia, Gennaro: 1998, 'Reference to Kinds Across Languages', Natural Language Semantics 6, 339-405.

Dayal, Veneeta: 2004, 'Number Marking and (In)Definiteness in Kind Terms', Linguistics and Philosophy 27, 393-450.

Dayal, Veneeta: 2006, 'Semantic Variation and Pleonastic Determiners: The Case of the Plural Definite Generic", to appear in Proceedings of $V$ Asian GLOW (http://www.rci.rutgers.edu/\%7Edayal/glow-circulation-06.pdf)

Endriss, Cornelia and Stefan Hinterwimmer: 2006, 'The Non-Uniformity of 
Quantificational Variability Effects: A Comparison of Singular Indefinites, Bare Plurals and Plural Definites', in S. Vogeleer (ed.), Bare Plurals, Indefinites and the Weak-Strong Distinction, Belgian Journal of Linguistics 19, 93-120.

Von Fintel, Kai: 1994, 'Restrictions on Quantifier Domains', Doctoral Dissertation, University of Massachusetts, Amherst.

Greenberg, Yael: 2003, Manifestations of Genericity, Routledge, NewYork/London.

Heim, Irene : 1992, 'Presupposition Projection and the Semantics of Attitude Verbs', Journal of Semantics 9, 183-221.

Hinterwimmer, Stefan: 2008, Q-Adverbs as Selective Binders: The Quantificational Variability of Free Relatives and Definite DPs, de Gruyter, Berlin/New York.

Krifka, Manfred, F. J. Pelletier, G. Carlson, A. ter Meulen, G. Chierchia and G. Link: 1995, 'Genericity: An Introduction', in G. Carlson and F. J. Pelletier (eds.), The Generic Book, 1-124, University of Chicago Press, Chicago.

Krifka, Manfred: 2004, 'Bare NPs: Kind-Referring, Indefinites, Both or Neither?', in R. B. Young and Y. Zhou (eds.), Proceedings of SALT XIII, CLC Publications, Cornell University, Ithaca.

Jacobson, Pauline: 1995, 'On the Quantificational Force of English Free Relatives', in E. Bach, E. Jelinek, A. Kratzer, B. H. Partee (eds.), Quantification in Natural Language, 451-486, Kluwer, Dordrecht.

Link, Godehard: 1983, 'The Logical Analysis of Plurals and Mass Terms: A Lattice-Theoretical Approach', in R. Bäuerle, C. Schwarze and A. von Stechow (eds.), Meaning, Use and Interpretation of Language, 302-323, de Gruyter, Berlin/New York.

Longobardi, Giuseppe: 2001, 'How Comparative is Semantics? A Unified Parametric Theory of Bare Nouns and Proper Names', Natural Language Semantics 9, 335-369.

Sternefeld, Wolfgang: 2005, 'Do Free Relative Clauses Have Quantificational Force?', in H.-M. Gaertner, S. Beck, R. Eckardt, R. Musan and B. Stiebels (eds.), Between 40 and 60 Puzzles for Krifka, http://www.zas.gwzberlin.de/publications/40-60-puzzles-for-krifka/pdf/sternefeld.pdf

De Swart, Henriette: 1993, Adverbs of Quantification: A Generalized Quantifier Approach, Garland, New York.

Wiltschko, Martina: 1999, 'Free Relatives as Indefinites', in K. Shahin, S. Blake and E.-S. Kim (eds.), Proceedings of WCCFL XVII, CSLI Publications, Stanford. 